\title{
Integrative Medicine: A Bridge between Biomedicine and Alternative Medicine Fitting the Spirit of the Age
}

\author{
H. J. Rogier Hoenders ${ }^{1}$, Martin T. Appelo ${ }^{2,3}$, Joop T. V. M. de Jong ${ }^{4,5,6}$ \\ ${ }^{1}$ Center for Integrative Psychiatry, Groningen, The Netherlands \\ ${ }^{2}$ Center for Psycho-Oncology, Het Behouden Huys, Haren, The Netherlands \\ ${ }^{3}$ Department of Clinical Psychology, University of Groningen, Groningen, The Netherlands \\ ${ }^{4}$ Amsterdam Institute for Social Science Research, University of Amsterdam, Amsterdam, The Netherlands \\ ${ }^{5}$ Boston School of Medicine, Boston, USA \\ ${ }^{6}$ Rhodes University, Grahamstown, South Africa \\ Email: hjr.Hoenders@lentis.nl
}

Received May 31 ${ }^{\text {st }}$ 2012; revised July $6^{\text {th }}$, 2012; accepted July $24^{\text {th }}$, 2012

\begin{abstract}
Complementary and alternative medicine (CAM) are increasingly used by people in first world countries, almost always in combination with biomedicine. The combination of CAM and biomedicine is now commonly referred to as "integrative medicine" (IM). In Groningen, The Netherlands, we founded a center for integrative psychiatry, offering conventional and complementary mental health care. Like other centers for integrative (mental) health we have mostly received positive reactions although there have been negative and even hostile reactions as well, using phrases like "quackery" and "betrayal". We will try to illustrate that these polarising qualifications, in which "the good" is being positioned against "the bad" in an over-simplified manner, are unnecessary and not useful. Moreover, it is unlikely that this polarisation will stall the growth of IM. It seems that integration is not only a current tendency in medicine, but also a trend fitting the contemporary spirit of the age in which integration seems to be the most common focus. It can be observed in religion, philosophy, spirituality and psychotherapy as well. This article will discuss the difference between differentiation and integration and will show that the focus on differentiation or integration varies with time, mostly rising as a reaction to each other. The transition from one period to the next is often met with resistance and criticism. If the integrative movement is to survive, it cannot do without differentiation and must find a middle way in which appropriate attention is being paid to keeping the integrated parts sufficiently differentiated and allowing them to keep their own identity.
\end{abstract}

Keywords: Integrative Medicine; Complementary Alternative Medicine; Polarisation; Integration

\section{Introduction}

The Latin word "integralis" means: "forming a greater entity". Integration stands for "fusing or making collaborate different parts into a larger whole" or "including into a whole". The opposite of integration is differentiation; the process whereby a homogeneous entity is being divided in parts with different qualities. Integration and differentiation are not mutually exclusive. They should rather be understood as movements of the same wave, or phenomena taking turns. When there is too much integration, the different parts lose their identity or experience a lack of autonomy. This provokes differentiation, leading them to profile themselves independently from each other. When there is too much differentiation, they lose sight of each other and each other's interests, which increases the risk of polarisation and conflict. This will invariably lead to a need for more integration.

This process can also be observed in medicine. At the end of the 19th and the beginning of the 20th century, the need for differentiation led to a change in medical laws and regulations in various countries (for instance the Flexner report in 1910 in the United States and the Health Care Implementation Act in 1865 in the Netherlands). These changes created a strict separation between recognised treatments on the one hand (which later became known as biomedicine or conventional medicine) and other forms of medicine (which later became known as alternative medicine). Besides the distinction between biomedicine and alternative medicine, a debate also arose between professsionals who favoured a reductionistic and biomedical approach of medicine and colleagues who preferred a more holistic or integrative approach. In the seventies and eighties of the 20th century George Engel was an influential physician from the last group. In response to the dominant reductionistic view of medicine, he formulated a biopsychosocial model. His criticism (Engel, 1992) of the biomedical model encompassed among other things: that illness perception can be insufficiently explained by biochemical changes (for instance, illness perception varies with culturally shared cognitions about diseases, illness-related behaviours and social support); that clinicians pay too little attention to personal factors and communication skills (for instance with regards to stimulating therapy adherence); and that behavioural and social variables can and do influence the course of an illness.

After more than a century of separation and conflicts between regular, biomedical medicine and alternative, holistic medicine, from 2000 on there is a tendency towards integration under the denominator of "integrative medicine" (Hollenberg, 2006; Hsiao et al., 2006; Jobst, 1998). Integrative medicine can be defined as "the practice of medicine that reaffirms the im- 
portance of the relationship between practitioner and patient, focuses on the whole person, is informed by evidence, and makes use of all appropriate therapeutic approaches, health care professionals and disciplines to achieve optimal health and healing" (Consortium, 2009). The most controversial part is the use of "all appropriate therapeutic approaches" as it includes the use of complementary and alternative medicine (CAM) within conventional hospitals/(care) delivery systems (Hoffer \& Hoenders, 2010).

“Complementary' stands for forms of diagnostics, treatments and prevention strategies that are based on theories accepted in biomedicine. These are usually substantiated by scientific argumentation, but for different reasons do not form part of biomedicine. Examples are massage therapy and the use of herbs and food supplements. Alternative treatments, such as healing and homeopathy, make use of other than the basic concepts of biomedicine. There is little proof for the efficacy of these treatments or there is considerable controversy about the scientific validation (Lake, 2007).

In integrative medicine the principles of evidence-based medicine are applied to regular, complementary and alternative treatments. This implies that in choosing an intervention, one should take into account the highest level of available scientific evidence about the different treatment options; the values, preferences and frame of reference of the patient; and the professsionalism and experience of the therapist (Sackett, Straus, Scott Richardson, Rosenberg, \& Haynes, 2000). The number of options in integrated medicine is larger than in regular health care (Hoenders, Appelo, Van den Brink, Hartogs, \& De Jong, 2011; Lake, 2007; Lake \& Spiegel, 2006), since CAM treatments are not excluded beforehand.

The European Parliament (1997) and the World Health Organization (2003) plead in favour of promoting integrative medicine (Chung, Hillier, Lau, Wong, Yeoh, \& Griffiths, 2011). However, this call is meeting a lot of resistance. There is an enormous heterogeneity in views and behaviour concerning CAM (Hirschkorn \& Bourgeault, 2005).

The movement is even sometimes labelled as "quackery" and the people who practice or promote CAM are sometimes disqualified as betrayers. This can be observed when reading the "rapid responses" to the editorial introducing this concept in biomedicine (Rees \& Weil, 2001) and more recently in a letter by Ernst (2012). Our center for integrative psychiatry also met these kind of criticisms (Kuipers \& Gijsman, 2006). In this essay we will try to illustrate that these polarising qualifications, in which "the good" is being positioned against "the bad" in an over-simplified manner, are unnecessary and not useful. The fact is that integration is not only a current tendency in medicine, but also a phenomenon that has manifested itself in the history of mankind in all types of fields and all sorts of ways. Not as an enemy of differentiation, but as a natural reaction to it.

\section{Manifestations of a Society Aimed at Integration}

"Integration" and "differentiation” both play a central role in the dynamics of life. Cells merge and split; people marry and separate; companies are fused and subdivided; and power blocks are formed and fall apart. The process of merging and separation is taking place on each level of life. It forms a returning theme in the history of humanity, and takes different forms in different fields, over and over again. In this article, we provide several typical examples from different spheres of life, restricting ourselves to the themes related to our own field: world view (philosophy, religion and spirituality), health care (treatment demand, pathways to care and psychotherapy), and scientific research.

\section{Philosophy}

The contemporary philosophy that evolved roughly after the Second World War is called "postmodernism”(Anderson, 1999; Bertens, 1994; Scruton, 2006). The core of this trend is the idea that objectivity and the absolute truth do not exist. There are many theories, ideologies, religions, convictions and principles, but history teaches us that none of these has profiled itself in such a way that it can be rightfully called "leading", "all-encompassing” or "universal”.

Lyotard (1979) called this "the end of the big stories". There is no winner and thus, there is no such thing as the ultimate truth or essential knowledge. As a result, postmodernism is not exclusively aimed at acquiring knowledge, but especially points at its ignorant, emotional, narrative, theory-bound and thus unstable foundation. If there is no absolute criterion, it is also not determined which goals we should pursue. According to one of the post-modern philosophies, existentialism, we are therefore doomed to freedom (Sartre, 1965). According to another philosophy, social constructivism, we are free to choose what we make of our lives, because everything changes all the time (Bertens, 1994). This implies fear and insecurity, but also provides unrestricted space to numerous equal, parallel ways to deal with things. Mainly because of this freedom, post-modern philosophy is offering a visionary framework for integrative thinking and acting.

\section{Religion and Spirituality}

Even though polarisation and hostilities between the major world religions still exist, and even though inter-religious tension is a risk factor for war and armed conflict (De Jong, 2010), there is a clear tendency of integration in the field of religion, especially in the Western world. This is caused by the secularisation of society, which has led to a decrease in popularity of institutionalised forms of religion, such as the Church. This has created a need for new forms of spirituality and interpretation, in which Eastern and shamanistic traditions and philosophies have played a considerable role in the last decennia. The way this new form of spirituality is being created, is characterised by diversity and the post-modern lack of claims on one exclusive source of the truth. This is accompanied by the freedom to choose how an individual would like to fulfil his spiritual needs.

Research shows that spirituality has a strong positive association with health (Koenig, 2000; Koenig, 2001). It also consistently shows that giving meaning to what happens to us, is more important for the wellbeing of a person than any particular religion. The experience of finding purpose is more important for the wellbeing of people than the capacity to clarify or to give a logical explanation for things (Lewis, Maltby \& Day, 2005; Scannell, Allen \& Burton, 2002; Steger \& Frazier, 2005).

\section{Demands for Care}

Also regarding to health needs and demands for care, a tendency towards integration can be observed. The expression 
"supply creates demand" implies that when people are making a choice, they take into account and use all available options. A demand for care is therefore determined for the most part by the available supply. Especially because of the internet, all healthrelated knowledge has become accessible to everyone. This has had a huge impact on the kind of health care demands people make. Nowadays patients want to choose their own treatment (Coulter \& Willis, 2004) and are increasingly requesting an integrated package of regular, complementary and alternative treatment methods (Hök, Wachtler, Falkenberg, \& Tishelman, 2007), not bothered by the differences in paradigms and working styles of CAM and biomedicine (Hoenders, Willgeroth, \& Appelo, 2008) and the ethical and scientific challenges resulting from it (Oguamanam, 2006).

Eisenberg et al. (1998) showed that CAM is being used on a large scale in the United States, usually in combination with regular treatments, and that there is an increase in use. In 1990, $34 \%$ of the Americans used CAM; by 1997 this percentage had increased to $42 \%$.

Even though patients do increasingly express demands for integrative care, they seem to anticipate that caregivers still restrict themselves to their own field of interest. About $60 \%$ $75 \%$ of patients appear to conceal the use of CAM to their doctor because of fear of disapproval or ridicule (VandeCreek, Rogers \& Lester, 1999). This is in sharp contrast with the fact that patients would like to receive information about CAM from their conventional providers. It would be advisable if doctors would address this need respectfully, since an open attitude towards nonregular treatment methods is essential (Hök et al., 2007): It improves the therapeutic relationship (Stevinson, 2001) and increases the impact of medical interventions (Koenig, 2000). It is also important to enquire about the use of CAM for medical-ethical reasons. Uncontrolled use of CAM can be dangerous, because of possible side-effects and interacttions with regular medicines (Ernst, 2002). In a study in Australia less than $3 \%$ of the population was aware of this (Walter \& Rey, 1998). In this regard it is worrisome that one in five patients combines herbs or foods supplements with medication (Eisenberg et al., 1998). An open conversation about CAM can take away misunderstandings and thereby prevent potentially dangerous situations.

These considerations led to our own research (Hoenders, Appelo, \& Milders, 2006), which showed that $42 \%$ of almost 600 psychiatric outpatients in the Northern Netherlands had used CAM. This figure is similar to older prevalence figures in psychiatric patients (53\%) (Knaudt, Connor, Weisler, Churchill, \& Davidson, 1999). We also studied the prevalence of CAM use among patients of General Practitioners (GPs). A survey of 900 patients showed that they had used CAM in $62 \%$ of cases (Borgemeester, Appelo, \& Hoenders, 2008). Both groups of patients report less than half of the cases of CAM use to their conventional doctor. This is also in agreement with prevalence rates offered by other researchers (VandeCreek et al., 1999; Wetzel, 1998). Half of the psychiatric patients and 65\% of the GP patients would like to receive more information about CAM and prefers that their conventional therapist would offer this. In contrast, the psychiatrists and GPs who were surveyed in this study heavily underestimated the use of CAM among their patients, and only one third of them was in favour of offering this information themselves. For one quarter of the psychiatrists and one third of the GPs CAM had an outspoken negative connotation. So, it seems that despite most patients favour CAM and integrative health care, a considerable number of conventional doctors are not willing to work in this way, creating a tension between health needs and supply.

\section{Psychotherapy}

Eventually, the struggle between different schools of thought in Western psychotherapy had come to an end. It was replaced by a so-called "Dodo bird verdict: Everybody has won, and all must have prizes” (Luborsky et al., 2002). This was done because empirical evidence had shown that the "specific ingredient' in any given therapy-that which theoretically makes it work-adds little to the nonspecific elements of psychotherapy (Asay \& Lambert, 1999). Moreover, this research has shown that clinical success is more a function of differences among therapists than among therapies (Wampold, 2001), and the success of therapists is primarily related to the quality of their alliance with patients (Baldwin, Wampold \& Imel, 2007; Luborsky et al., 2002).

This revaluation of nonspecific therapy factors is also being stimulated by an increasing collaboration between behaviouroriented sciences such as neurology, biology and experimental, social and clinical psychology. The results of this interdisciplinary research questions the existence of the free will: the neocortex appears to be less dominant and therefore has less influence on our behaviour than it would like us to believe (Dijksterhuis, 2008; Lamme, 2010). It seems that we are predominantly controlled by automatic neural networks. Someone who would like to change his behaviour does not benefit much from a wonderful all-encompassing theory, but needs the discipline to replace all old automatisms with new ones that fit into his own (small, but subjectively significant) story (Appelo, 2011; Brewin, 2006). The treatment method that facilitates this type of learning, is no longer forcefully dictated by a particular viewpoint or school of thought. In line with the principles of evidence-based medicine, this integrative method results from the interaction between the (preferences of the) patient, the (expertise and experience of the) therapist and the number of effective interventions that are available at that moment. This gives the psychotherapeutic practice an integrated, eclectic character (Korrelboom \& Ten Broeke, 2004).

Another form of integration in psychotherapy is that of East and West. Eastern philosophies are increasingly being integrated into Western (psycho) therapies; examples are mindfulness and Acceptance and Commitment Therapy (ACT) (Kabat-Zinn, 2003). So, it seems that also in psychotherapy there are many developments with a tendency towards integration.

\section{Scientific Research}

Although there still are well-defined schools of thought in the world of science with their own methodological preferences, we also see, especially in health care, a growing space for the equal coexistence of different research methods (Plochg, Juttman, Klazinga, \& Mackenbach, 2007; Walach, Falkenberg, Fønnebø, Lewith, \& Jonas, 2006). This is facilitated by the criticism of the doctrine of the randomised controlled trial (RCT) as a "sacred" scientific research method (Ottenbacher \& Hinderer, 2001). This criticism is predominantly based on the difference between internal validity, or efficacy (does a method or intervention work as such?) and external validity, or effecttiveness (is it beneficial in a certain context?). Proven efficacy does not say much about effectiveness, as what works in a large 
group on average does not per se apply to all individuals in various contexts. On the other hand, effectiveness does not simply imply efficacy, because what works for a person in a particular situation, cannot always be generalised to a group.

If an intervention with only one mode of action is being studied, as is the case with medication, and if a subject does not prefer the experimental condition over the control condition (because he cannot know the difference between the two), it is indicated to establish the internal validity of the intervention first. In this case, the RCT is the research method of choice. If however the expectation of the result and the preference of subjects play a role and these are not the same for the experimental and the control condition (as is the case with almost all psychological and non-placebo-controlled medication research in health care), establishment of the external validity is indicated first. Observational, quasi-experimental and mixedmethods research is the method of choice in this case (Barry, 2006; Plochg et al., 2007). This offers possibilities for CAM (Barry, 2006) as most CAM users have a strong preference and therefore it is difficult to do RCTs for CAM therapies. Although in biomedicine it is common to start with randomised trials first, possibly later followed with effectiveness studies, in CAM it seems acceptable to work the other way around. To start assessing the effectiveness in a certain context and verifying it later in a RCT. This also makes sense as in biomedicine new pharmacological compounds are only allowed on the market after assessing efficacy and safety in RCTs, but most CAM are already being used, even though efficacy has not been established yet. So, it seems that it depends entirely on the research question, kind of treatment and circumstances, which kind of research design is needed. No design (not even RCT) can be considered best in all circumstances (Walach et al., 2006). This calls for an integrated research approach.

\section{Discussion}

This essay suggests that the integrative movement in health care does not stand on itself. It is a phenomenon that is manifesting itself worldwide and in different aspects of daily life. It follows a period in which differentiation took central stage but did not lead to absolute, unquestionable truths.

The conclusion that integrative health care fits into the spirit of the time therefore seems justified. However, there is a chance that, with continuing integration, this movement will develop into another direction. The different parts in this case might eventually lose their identity, develop a need for autonomy and try to promote more differentiation. The dynamics of the processes of differentiation and integration show that both poles are connected (similar to the perpetual dynamics and balance between yin and yang in Eastern philosophy or the theory of dialectics). If the integrative movement wants to survive, it will have to make sure that the balance is not lost.

In other words: a continuing integrative movement cannot do without differentiation and must find a middle way in which appropriate attention is being paid to keeping the integrated parts sufficiently differentiated and allowing them to keep their own identity. Then, integrative health care predominantly means a good and equal collaboration between parts that are well differentiated. In this regard it would be useful if everyone who is involved in the process, critically contributes to the debate and raises the alarm once the balance between differentiation and integration is getting lost. In the last few years a dis- torted balance due to a lack of criticism or supervision has become visible in various spheres-e.g., the worldwide financial crisis and fraud in scientific research.

Finally, it would be interesting to raise the question why in the process of integration and differentiation people may feel the need for polarisation and rowing against the flow, instead of contributing to the debate. We think that the main reason why people would protest against integration is that they do not consider themselves sufficiently profiled and recognised in the process of differentiation. After all, it looks like integration works against one's own identity. Especially when a person's identity has not been satisfactorily established during the process of differentiation, he may fear that integration will destroy it. This phenomenon is visible in the viewpoint of Kuipers and Gijsman (2006), who present as an argument against the psychiatric branch of the integrative movement, that it has taken regular psychiatry already a lot of efforts to be seen as a normal part of medicine. The resistance against integration is then related to the lack of a clear identity. Developing such an identity is a good thing. But fighting against something else is, in our opinion, not an appropriate method to reach this goal. It would be better to invest in the profiling of your own message and methods. Once we feel that we are being carried away, against our will or not, in an integrative movement, we do not have to be afraid that we will lose ourselves in it. We can get out of it on our own, or take part in the larger whole and help create something that is more than the sum of its parts, all the while making sure that we can still recognise ourselves in what we are doing. That will assist in finding and keeping the middle road between preservation of one's own identity and integration into a larger whole.

\section{Acknowledgements}

The authors thank E. H. Bos and N. K. Vollbehr for their assistance in preparing the manuscript.

\section{REFERENCES}

Anderson, P. (1999). The origins of postmodernity. London: Verso.

Appelo, M. (2011). The multi layered brain. Reflection and discipline in working for change [Het gelaagde brein. Reflectie en discipline bij het werken aan verandering]. Amsterdam: Boom.

Asay, T. R., \& Lambert, M. J. (1999). The empirical case of the common factors in psychotherapy: quantitative findings. In M. A. Hubble, B. L. Duncan, \& S. D. Miller (Eds.), The heart and soul of change: what works in therapy (pp. 23-55). Washington DC: American Psychological Association. doi:10.1037/11132-001

Baldwin, S. A., Wampold, B. E., \& Imel, Z. E. (2007). Untangling the alliance-outcome correlation: Exploring the relative importance of therapist and patient variability in the alliance. Journal of Consulting and Clinical Psychology, 65, 842-852. doi:10.1037/0022-006X.75.6.842

Bertens, H. (1994). The idea of the postmodern: A history. London: Routledge.

Borgemeester, S., Appelo, M. T., \& Hoenders, H. J. R. (2008). Complementary and alternative medicine in family practice: Opinions of patients and GP's [Complementaire en alternatieve geneeswijzen in de huisartsenpraktijk: De mening van huisartsen en patiënten]. $G G z$ Scientific, 12, 26-32.

Brewin, C. R. (2006). Understanding cognitive behaviour therapy: A retrieval competition account. Behaviour Research and Therapy, 44, 765-784. doi:10.1016/j.brat.2006.02.005

Chung, V. C. H., Hillier, S., Lau, C. H., Wong, S. Y. S., Yeoh, E. K., \& Griffiths, S. M. (2011). Referral to and attitude towards traditional 


\section{H. J. R. HOENDERS ET AL.}

Chinese medicine amongst Western medical doctors in postcolonial Hong Kong. Social Science \& Medicine, 72, 247-255. doi:10.1016/j.socscimed.2010.10.021

Consortium, T. (2009). URL (last checked 1 February 2012). http://www.imconsortium.org/

Coulter, I. D., \& Willis, E. M. (2004). The rise and rise of complementary and alternative medicine: A sociological perspective. Medical Journal of Australia, 180, 587-589.

De Jong, J. T. V. M. (2010). A public health framework to translate risk factors related to political violence and war into multi-level preventive interventions. Social Science \& Medicine, 70, 71-79. doi:10.1016/ j.socscimed.2009.09.044

Dijksterhuis, A. (2008). The smart unconsious. Thinking with feeling [Het slimme onbewuste. Denken met gevoel]. Amsterdam: Bert Bakker.

Eisenberg, D. M., Davis, R. B., Ettner, S. L., Appel, S., Wilkey, S., Van Rompay, M. et al. (1998). Trends in alternative medicine use in the United States, 1990-1997. JAMA, 280, 1569-1575. doi:10.1001/jama.280.18.1569

Engel, G. L. (1992). How much longer must medicine's science be bound by a seventeenth century world view? Psychotherapies and Psychosomatics, 57, 3-16. doi:10.1159/000288568

Ernst, E. (2002). The risk-benefit profile of commonly used herbal therapies: Ginkgo, St. John's Wort, Ginseng, Echinacea, Saw Palmetto, and Kava. Annals of Internal Medicine, 136, 42-53.

Ernst, E. (2012). College of medicine or college of quackery? British Medical Journal, 343, d4370. doi:10.1136/bmj.d4370

European Parliament (1997). A European approach to non conventional medicines. URL (last checked 1 February 2012).

http://assembly.coe.int/main.asp?Link=/documents/workingdocs/doc 99/edoc8435.htm

Hirschkorn, K. A., \& Bourgeault, I. L. (2005). Conceptualizing mainstream health care providers' behaviours in relation to complementary and alternative medicine. Social Science \& Medicine, 61, 157170. doi:10.1016/ j.socscimed.2004.11.048

Hoenders, H. J. R., Appelo, M. T., \& Milders, C. F. A. (2006). Complementary and alternative medicine and psychiatry: Opinions and psychiatrists and patients [Complementaire en alternatieve geneeswijzen en psychiatrie: meningen van patiënten en psychiaters]. Dutch Journal of Psychiatry, 9, 733-737.

Hoenders, H. J. R., Appelo, M. T., Van den Brink, H., Hartogs, B. M. A., \& De Jong, J. T. V. M. (2011). The Dutch complementary and alternative medicine (CAM) protocol. Journal of Alternative and Complementary Medicine, 17, 1-5. doi:10.1089/acm.2010.0762

Hoenders, H. J. R., Willgeroth, F. C., \& Appelo, M. T. (2008). Western and alternative medicine: A comparison of paradigms and methods. The Journal of Alternative and Complementary Medicine, 14, 894896. doi:10.1089/acm.2007.0645

Hoffer, C., \& Hoenders, H. J. R. (2010). Complementary, alternative and religious medicine [Religieuze, complementaire en alternatieve geneeswijzen]. In J. T. V. M. de Jong, \& S. Colijn (Eds.), Cultural psychiatry (pp. 451-468). Amsterdam: De Tijdstroom.

Hök, J., Wachtler, C., Falkenberg, T., \& Tishelman, C. (2007). Using narrative analysis to understand the combined use of complementary and biomedically oriented health care. Social Science \& Medicine, 65, 1642-1653. doi:10.1016/j.socscimed.2007.05.031

Hollenberg, D. (2006). Uncharted ground; patterns of professional interaction among complementary/ alternative and biomedical practitioners in integrative health care settings. Social Science \& Medicine, 62, 731-744. doi:10.1016/j.socscimed.2005.06.030

Hsiao, A., Ryan, G. W., Hays, R. D., Coulter, I. D., Andersen, R. M., \& Wenger, N. S. (2006). Variations in provider conceptions of integrative medicine. Social Science \& Medicine, 62, 2973-2987. doi:10.1016/j.socscimed.2005.11.056

Jobst, K. Z. (1998). Toward integrated healthcare: Practical and philosophical issues at the heart of the integration of biomedical, complementary, and alternative medicines. The Journal of Alternative and Complementary Medicine, 4, 123-126. doi:10.1089/acm.1998.4.123

Kabat-Zinn, J. (2003). Mindfulness Based Stress Reduction (MBSR). Constructivism in the Human Sciences, 8, 73-83.
Knaudt, P. R., Connor, K. M., Weisler, R. H., Churchill, L. E., \& Davidson, J. R. (1999). Alternative therapy use by psychiatric outpatients. The Journal of Nervous and Mental Disease, 187, 692-695. doi:10.1097/00005053-199911000-00007

Koenig, H. G. (2000). Religion, spirituality, and medicine: Application to clinical practice. JAMA, 284, 1708-1709. doi:10.1001/jama.284.13.1708

Koenig, H. G. (2001). Religion and medicine 4: Religion, physical health and clinical implications. International Journal of Psychiatry in Medicine, 31, 321-336. doi:10.2190/X28K-GDAY-75QV-G69N

Korrelboom, C. W., \& Ten Broeke, E. (2004). Integrated cognitive behavioural therapy [Geïntegreerde cognitieve gedragstherapie]. Bussum: Coutinho.

Kuipers, T., \& Gijsman, H. J. (2006). Response to "Integrated psychiatry" and "Complementary and alternative medicine and psychiatry" [Reactie op "Integrale psychiatrie" en "Complementaire en alternatieve geneeswijzen (CAG) en psychiatrie”]. Dutch Journal of Psychiatry, 48, 981-982.

Lake, J. H. (2007). Textbook of integrative mental health care. New York: Thieme Medical Publishers.

Lake, J. H., \& Spiegel, D. (2006). Complementary and alternative treatments in mental health care. Washington DC, London: American Psychiatric Publishing.

Lamme, V. (2010). Free will does not exist: About who is really in charge in our brain [De vrije wil bestaat niet. Over wie er echt de baas is in het brein]. Amsterdam: Bert Bakker.

Lewis, C. A., Maltby, J., \& Day, L. (2005). Religious orientation, religious coping and happiness among UK adults. Personality and Individual Differences, 38, 1193-1202. doi:10.1016/j.paid.2004.08.002

Luborsky, L., Rosenthal, R., Diguer, L., Andrusyna, T. P., Berman, J. S., Levitt, J. et al. (2002). The dodo bird verdict is alive and wellmostly. Clinical Psychology: Science and Practice, 9, 2-12. doi:10.1093/clipsy.9.1

Lyotard, J. F. (1979). The postmodern condition: A report on knowledge [La condition postmoderne: rapport sur le savoir]. Paris, France: Minuit.

Oguamanam, C. (2006). Biomedical orthodoxy and complementary and alternative medicine: Ethical challenges of integrating medical cultures. The Journal of Alternative and Complementary Medicine, 12, 577-581. doi:10.1089/acm.2006.12.577

Ottenbacher, K. J., \& Hinderer, S. R. (2001). Evidence-based practice. Methods to evaluate individual patient improvement. American Journal of Physical Medical Rehabilitation, 80, 786-796. doi:10.1097/00002060-200110000-00014

Plochg, T., Juttmann, R. E., Klazinga, N. S., \& Mackenbach, J. P. (2007). Manual for healthcare research [Handboek gezondheidszorgonderzoek]. Houten: Bohn Stafleu van Loghum.

Rees, L. \& Weil, A. (2001). Integrated medicine. BMJ, 322, 119. doi:10.1136/bmj.322.7279.119

Sackett, D. L., Straus, S. E., Scott Richardson, W., Rosenberg, W., \& Haynes, R. B. (2000). Evidence based medicine. Edinburgh: Churchill Livingstone.

Sartre, J.-P. (1965). Existentialism is a humanism [L'existentialisme est un humanisme]. Paris: Les Editions Nagel.

Scannell, E. D., Allen, F. C. L., \& Burton, J. (2002). Meaning in life and positive and negative well-being. North American Journal of Psychology, 4, 93-112.

Scruton, R. (2006). Modern philosophy: from Descartes to Wittgenstein [Moderne filosofie. Van Descartes tot Wittgenstein]. Utrecht: Bijleveld.

Steger, M. F., \& Frazier, P. (2005). Meaning in life: One link in the chain from religiousness to well-being. Journal of Counseling Psychology, 52, 574-582. doi:10.1037/0022-0167.52.4.574

Stevinson, C. (2001). Why patients use complementary and alternative medicine. In E. Ernst, M. H. Pittler, \& B. Wider (Eds.), The desktop guide to complementary and alternative medicine, an evidence based approach. Edinburgh: Mosby, by Hartcourt Publishers Limited.

VandeCreek, L., Rogers, E., \& Lester, J. (1999). Use of alternative therapies among breast cancer outpatients compared with the general population. Alternative Therapies in Health and Medicine, 5, 71-76.

Walach, H., Falkenberg, T., Fønnebø, V., Lewith, G., \& Jonas, W. B. 


\section{H. J. R. HOENDERS ET AL.}

(2006). Circular instead of hierarchical: Methodological principles for the evaluation of complex interventions. BMC Medical Research Methodology, 6, 29. doi:10.1186/1471-2288-6-29

Walter, G. \& Rey, J. M. (1998). The relevance of herbal treatments for psychiatric practice. Australian and New Zealand Journal of Psychiatry, 33, 482-489. doi:10.1046/j.1440-1614.1999.00568.x

Wampold, B. E. (2001). The great psychotherapy debate: Models, methods and findings. Mahwah, NJ: Lawrence Erlbaum Associates. Wetzel, M. S. (1998). Courses involving complementary and alternative medicine at US medical schools. The Journal of the American Medical Association, 280, 784-787. doi:10.1001/jama.280.9.784

World Health Organization (2003). Traditional Medicine Strategy 2002-2005. URL (last checked 1 February 2012). www.who.int 